\title{
Electrochemical determination of gadolinium and plutonium solvation properties in liquid gallium at high temperature.
}

\author{
Jörgen Finne ${ }^{\mathrm{a}}$, Gérard Picard ${ }^{\mathrm{b}}$, Sylvie Delpech ${ }^{\mathrm{b} *}$, Eric Walle ${ }^{\mathrm{a}}$, Olivier Conocar ${ }^{\mathrm{c}}$, \\ Annabelle Laplace ${ }^{c}$ and Jérôme Lacquement ${ }^{c}$ \\ ${ }^{a}$ EDF R\&D - MMC ; Site des Renardières \\ Ecuelles - Avenue des Renardières 77818 Moret Sur Loing Cedex France \\ ${ }^{\mathrm{b}}$ LECA CNRS UMR 7575 Ecole Nationale Supérieure de Chimie de Paris \\ 11, rue Pierre et Marie Curie 75231 Paris cedex 05 France \\ ${ }^{\mathrm{c}}$ CEA Marcoule DRCP/SCPS/LPP
}

Bât. 399 - BP 1717130207 Bagnols / Cèze cedex

* author for correspondance

\begin{abstract}
:
Pyrochemical separation processes [1,2] are considered for the treatment of spent nuclear fuel and particularly for the separation of fission products from actinides. In order to estimate the efficiency and selectivity for various extraction processes based on a molten salt/solvent metal separation technique, we have to know the properties of the elements to be extracted in each solvent, notably their activity coefficients in the two phases. The classical way to measure the activity coefficient of an element in a liquid metal is to use a concentration cell whose the electromotive force (emf) is measured. This type of cell involves 2 electrodes (i) the element investigated in its pure metallic form and (ii) the element solvated in the solvent metal. The electrolyte used for this study is a chloride melt which contains the element under consideration as a solute. In this paper, an effort was made to measure activity coefficients in liquid metals by means of electrochemical techniques rather than potentiometric technique. The experimental protocol was optimized by measuring the activity coefficient of gadolinium in liquid gallium (solvent metal) $\gamma(\mathrm{Gd} / \mathrm{Ga})$ at $530^{\circ} \mathrm{C}$ for several amounts of gadolinium in gallium and $\log \gamma(\mathrm{Gd} / \mathrm{Ga})$ was determined to be equal to -10.17 (mole fraction scale). Then, the temperature dependence of the activity coefficient was determined in the range of 535$630^{\circ} \mathrm{C}$. It appears that $\log \gamma(\mathrm{Gd} / \mathrm{Ga})$ varies linearly with the reciprocal value of $\mathrm{T}$, thus following the theoretical variation. The electrochemical method was also performed to the determination of activity coefficient of plutonium in liquid gallium at $560^{\circ} \mathrm{C}$. The value of $\log \gamma(\mathrm{Pu} / \mathrm{Ga})$ so obtained is equal to -8.04 (mole fraction scale). This value was confirmed using electrochemical and potentiometric measurements with a plutonium saturated gallium electrode.
\end{abstract}

Keywords: Pyrochemical processes, Plutonium, Gadolinium, Molten salt, Solvent metal, Activity coefficients, Electrochemistry.

\section{Introduction}


The activity coefficients $(\gamma(\mathrm{M}))$ are essential in order to accurately predict distribution coefficients of different elements in a molten salt / liquid metal system. The chemical equilibrium of an element $\mathrm{M}$ between a molten (fluoride or chloride) salt (MS) and a solvent metal (SM) (containing reductive species such as $\mathrm{Li}$ or $\mathrm{Al}[1])$ is given by:

$$
\mathrm{MX}_{\mathrm{z}}(\mathrm{MS})+\mathrm{Li}(\mathrm{SM}) \leftrightarrow \mathrm{M}(\mathrm{SM})+\mathrm{zLiX}(\mathrm{MS})
$$

The distribution coefficient $\mathrm{D}_{\mathrm{M}}$ corresponds to the ratio of the mole fraction of $\mathrm{M}$ in the solvent metal over its mole fraction in molten salt. Its expression is given by:

$$
\log \mathrm{D}_{\mathrm{M}}=\log \mathrm{K}^{\mathrm{o}} \mathrm{M}+\mathrm{z} \log \mathrm{D}_{\mathrm{Li}}+\log \frac{\gamma^{\mathrm{z}}(\mathrm{Li} / \mathrm{SM})}{\gamma(\mathrm{M} / \mathrm{SM})}+\log \frac{\gamma\left(\mathrm{MX}_{\mathrm{Z}} / \mathrm{MS}\right)}{\gamma^{\mathrm{z}}(\mathrm{LiX} / \mathrm{MS})}
$$

In this relation, $K_{M}$ is the standard thermodynamic constant of the equilibrium (1), $\mathrm{D}_{\mathrm{Li}}$ the distribution coefficient of $\mathrm{Li}$ and $\gamma$ the activity coefficients of either $\mathrm{Li}, \mathrm{M}, \mathrm{LiX}$ and $\mathrm{MX}_{\mathrm{z}}$ in the solvent metal and in the molten salt. The extraction efficiency $\operatorname{EFF}(M)$ of the element $M$ is given by the following relation:

$$
\mathrm{EFF}(\mathrm{M})=1 /\left(1+\frac{1}{\mathrm{D}_{\mathrm{M}}} * \frac{\mathrm{n}_{\mathrm{MS}}}{\mathrm{n}_{\mathrm{SM}}}\right)
$$

where $n_{M S}$ and $n_{S M}$ are respectively the number of moles of molten salt and solvent metal involved in the process. Assessment of the extraction process needs the knowledge of activity coefficients in the molten salt and in the solvent metal. Nevertheless, comparison between experimental and calculated distribution coefficients of plutonium $\mathrm{D}_{\mathrm{Pu}}[2,3]$ shows that the activity coefficients in molten salt are not really determinant to accurate (accurate n'est pas un verbe - plutôt evaluate) the process compared to the activity coefficients in the solvent metal. A lot of data on these activity coefficients are available in the literature [4]. However, there are few data on the activity coefficients of actinides, except for thorium, uranium and (prop.: (...) uranium and plutonium. For the latter one, some data are missing a for example in gallium. The variation of plutonium activity coefficient as a function of temperature is not available in this metallic solvent.) only one for plutonium in gallium at a higher temperature [5]. Hence, effort has been done to develop an electrochemical method in order to measure the activity coefficient of different elements in liquid metals.

\section{2- Principle of determination of an activity coefficient in a liquid metal}

2.a-Analytical relations used for this determination

The method is based on an indirect determination of the electromotive force emf of the concentration cell described Fig. 1. The expression of emf is given by:

$$
\mathrm{emf}=\frac{2.3 \mathrm{RT}}{\mathrm{zF}} \log \mathrm{a}(\mathrm{M} / \mathrm{SM})
$$

Where $\mathrm{R}$ is the ideal gas constant, $\mathrm{T}$ the temperature, $\mathrm{F}$ the Faraday constant, $\mathrm{z}$ the number of electrons and $\mathrm{a}(\mathrm{M} / \mathrm{SM})$ the activity of $\mathrm{M}$ in the solvent metal.

The general expression for activity is:

$$
\mathrm{a}(\mathrm{M} / \mathrm{SM})=\mathrm{x}(\mathrm{M} / \mathrm{SM}) * \gamma(\mathrm{M} / \mathrm{SM})
$$


Where $\mathrm{x}(\mathrm{M})$ is the mole fraction and $\gamma(\mathrm{M})$ the activity coefficient of the element $\mathrm{M}$.

From (4) and (5), we can derive the following relation:

$$
\mathrm{emf}=\frac{2.3 \mathrm{RT}}{\mathrm{zF}} \log \gamma(\mathrm{M} / \mathrm{SM})+\frac{2.3 \mathrm{RT}}{\mathrm{zF}} \log \mathrm{x}(\mathrm{M} / \mathrm{SM})
$$

showing that emf only depends on the activity of $\mathrm{M}$ in the metal phase.

The experimental determination of emf is generally indirect because of the use of a reference electrode. Considering the two half cells constituted by (Reference/M pure solid as reference state) and (Reference/M in solvent metal) (Fig.1), we can demonstrate that emf is given by the difference of two half cell potentials $\left(\Delta \mathrm{E}_{1}-\Delta \mathrm{E}_{2}\right)$ defined by:

$$
\begin{aligned}
& \Delta \mathrm{E}_{1}=\mathrm{E}^{\circ} \mathrm{MX}_{\mathrm{Z}} / \mathrm{M}+\frac{2.3 \mathrm{RT}}{\mathrm{zF}} \log \frac{\mathrm{a}\left(\mathrm{MX}_{\mathrm{Z}}\right)}{\mathrm{a}(\mathrm{M})} \\
& \Delta \mathrm{E}_{2}=\mathrm{E}^{\circ} \mathrm{MX}_{\mathrm{Z}} / \mathrm{M}+\frac{2.3 \mathrm{RT}}{\mathrm{zF}} \log \frac{\mathrm{a}\left(\mathrm{MX}_{\mathrm{Z}}\right)}{\mathrm{a}(\mathrm{M} / \mathrm{SM})}
\end{aligned}
$$

Where, $\mathrm{E}^{\circ}{ }_{\mathrm{MXz} / \mathrm{M}}$ is the standard redox potential of the system $\mathrm{MX}_{\mathrm{Z}} / \mathrm{M}$ and a( $\left(\mathrm{MX}_{\mathrm{z}}\right)$ the activity of $\mathrm{MX}_{\mathrm{z}}$ in molten salt, $\mathrm{a}(\mathrm{M})$ the activity of the pure element $\mathrm{M}(\mathrm{a}(\mathrm{M})=1)$ and $\mathrm{a}(\mathrm{M} / \mathrm{SM})$ the activity of $\mathrm{M}$ in solvent metal.

\section{2.b- Half cell potential measurements}

$\Delta \mathrm{E}_{1}$ is measured in situ via electrodeposition of the element $\mathrm{M}$ on an inert working electrode via the cathodic reduction of $\mathrm{MX}_{\mathrm{n}}$. The behavior of the working electrode is then similar to that of pure $\mathrm{M}$. The deposition is realized by using a galvanodynamic method which consists in scanning the current $I(0 \rightarrow-10 \mathrm{~mA} \rightarrow 20 \mathrm{~mA})$ at $0.1 \mathrm{~mA} / \mathrm{s}$ and recording the corresponding potential variation. $\Delta \mathrm{E}_{1}$ corresponds to the potential value recorded when the current is equal to zero. Its value is directly measured on the galvanodynamic curve for $I$ equal to 0 .

$\Delta \mathrm{E}_{2}$ is the equilibrium potential measured at the interface of the solvent metal containing a known amount of the element $\mathrm{M}$ and the molten salt containing $\mathrm{MX}_{\mathrm{z}}$ (at the same concentration of that used for $\Delta \mathrm{E}_{1}$ measurement). The element $\mathrm{M}$ is introduced into the solvent metal by electrochemical reduction of $\mathrm{MX}_{\mathrm{z}}$ on the solvent metal working electrode. The potential applied during the coulometry is previously determined from a voltammetric study which allows us to identify the redox systems. The mole fraction of $\mathrm{M}$ introduced into the solvent metal is controlled by measuring the quantity of electric charge $\mathrm{Q}$ involved during the coulometry. After electrochemical introduction of $\mathrm{M}$ in the solvent metal, $\Delta \mathrm{E}_{2}$ is recorded as a function of time until stabilization.

From these measurements, emf is calculated and the activity coefficient $\gamma(\mathrm{M})$ determined using relation (6).

\section{2.c- Validation of the method}

Two different experiments have been realized to validate the method. In the first one, several successive coulometries are performed to increase the mole fraction of $\mathrm{M}, \mathrm{x}(\mathrm{M})$, in the 
solvent metal. After each coulometry, the potentials $\Delta \mathrm{E}_{1}$ and $\Delta \mathrm{E}_{2}$ are measured and emf calculated. Then, the variation of is drawn as a function of $\log x(\mathrm{M})$. The comparison of the experimental slope obtained with the theoretical one given by relation (6) allows us to validate the method. According to relation (6), y-intercept gives the value of $\log \gamma(\mathrm{M} / \mathrm{SM})$. In the second one, the mole fraction of $\mathrm{M}$ in the solvent metal is constant and measurements of $\Delta \mathrm{E}_{1}$ and $\Delta \mathrm{E}_{2}$ are realized for several temperatures and the activity coefficient calculated for each temperature. The theoretical variation of $\log \gamma(\mathrm{M})$ as a function of $1 / \mathrm{T}$ has to be linear.

The method was first performed for the determination of the activity coefficient of gadolinium and plutonium in liquid gallium using the molten salt $\mathrm{NaCl}-\mathrm{CaCl}_{2}$ (50-50 mol\%). Some preliminary results obtained for the activity coefficient of gadolinium at $530^{\circ} \mathrm{C}$ have already been published [6]. The aim of this paper is to improve the results for gadolinium considering the influence of temperature (ranging between 535 and $630^{\circ} \mathrm{C}$ ) and to present the results obtained for plutonium behavior in liquid gallium at $560^{\circ} \mathrm{C}$.

\section{3- Experimental}

3.a-Technical

$\mathrm{NaCl}$ (Aldrich, 99,99\% purity) and $\mathrm{CaCl}_{2}$ (Aldrich, 99,99\% purity) are weighed and mixed in a glassy carbon (SGL Carbon) crucible which is subsequently introduced inside an electrochemical reactor made of quartz and constituted of two parts (top and bottom). The air tightness is maintained using a locking screw (Fig. 2).

The mixed salts are dried under argon gas (Air Liquide) before melting. The purification of melt is realized by bubbling $\mathrm{HCl}$ (PRAXAIR) for $30 \mathrm{~min}$ which allows elimination of oxygen and moisture [7]. Residual $\mathrm{HCl}$ is eliminated by argon gas bubbling. All the experiments are performed under argon gas atmosphere.

The reference electrode (Fig.2) is made of a porous alumina tube filled with the molten salt containing $0.75 \mathrm{~mol} / \mathrm{kg}$ of $\mathrm{AgCl}$ (Aldrich, 99.99\% purity). The electrical contact is realized with a silver wire (1mm diameter) (Goodfellow, 99.999\% purity) and the reference redox system is $\mathrm{AgCl} / \mathrm{Ag}$. In our experimental conditions, the potential of $\mathrm{AgCl} / \mathrm{Ag}$ redox system is equal to $-1.15 \mathrm{~V} /\left(\mathrm{Cl}_{2}(1 \mathrm{~atm}) / \mathrm{Cl}^{-}(\right.$activity=1)). The counter electrode is made of a tungsten wire (1 $\mathrm{mm}$ diameter) (Goodfellow, 99.99\% purity). The working electrode is a tungsten wire (1mm diameter) (Goodfellow, 99.99\% purity) for cyclic voltammetric and galvanodynamic measurements. For the activity measurements of $\mathrm{Gd}$ and $\mathrm{Pu}$ in liquid gallium, a quartz container filled with gallium (Aldrich, 99.999\% purity) is used (Fig.2). The electrical contact is made using a tungsten wire isolated from the electrolyte. The weight of gallium introduced in the liquid metal container is close to $10 \mathrm{~g}$.

The electrochemical cell is introduced in a tubular furnace $(80 \mathrm{~cm}$ diameter) connected to a regulation monitor provided by TANER/France. Electrochemical measurements are performed with an EG\&G potentiostat-galvanostat model 263 coupled with a PC computer.

$\mathrm{GdCl}_{3}$ (Aldrich, $99.99 \%$ purity) is weighed $(2 \mathrm{~g})$ in glove box under argon atmosphere and transferred into the electrochemical reactor without any contact with air.

\section{3.b-. Particular experimental procedure for measurements with plutonium}

The experiments performed with plutonium are carried out in a glove box with a negative pressure regulation system, containing the furnace. The $\mathrm{NaCl}$ and $\mathrm{CaCl}_{2}$ salts are weighed, melted, purified, cooled and solidified in the crucible and transferred in the glove box. Powder of $\mathrm{PuO}_{2}$ (CEA) is added in the crucible before melting. $\mathrm{PuO}_{2}$ is dissolved by carbochlorination by bubbling in the melt gaseous $\mathrm{Cl}_{2}$ (Praxair) through a graphite tube (ATJ 49 , Graphitec) in melt for 1 hour in the presence of 3 porous graphite bars (6 mm diameter) (Goodfellows, $99.99 \%$ purity). The reaction occurring is: 


$$
\mathrm{PuO}_{2}(\mathrm{~s})+2 \mathrm{Cl}_{2}(\mathrm{~g})+\mathrm{C} \rightarrow \mathrm{PuCl}_{4}+\mathrm{CO}_{2}(\mathrm{~g})
$$

The reactor is isolated under $\mathrm{Cl}_{2}$ atmosphere for 3 days and then, put under argon atmosphere. $\mathrm{PuCl}_{4}$ being not stable under argon atmosphere is reduced to form dissolved $\mathrm{PuCl}_{3}$. A sample was taken and analyzed by $\alpha$-counting. It indicates a concentration of plutonium equal to $0.042 \mathrm{~mol} / \mathrm{kg}$ which corresponds to a dissolution efficiency close to $90 \%$.

\section{4- Electrochemical determination of the activity coefficient of gadolinium in liquid gallium.}

4.a-Measurement of $\Delta E_{1}$ by galvanodynamic method

Measurements of $\Delta \mathrm{E}_{1}$ and $\Delta \mathrm{E}_{2}$ have been performed at $530^{\circ} \mathrm{C}$ after several addition of gadolinium in gallium $\left(\mathrm{x}(\mathrm{Gd} / \mathrm{Ga})\right.$, being from $3.10^{-4}$ to $10^{-3}$. Fig. 3 presents the variation of emf $\left(=\Delta \mathrm{E}_{1}-\Delta \mathrm{E}_{2}\right) v s$ the logarithm of the mole fraction of gadolinium in gallium. The linear variation given Fig. 3 is drawn with the theoretical slope equal to 0.05308. In this condition, the y-intercept leads to the determination of $\log \gamma(\mathrm{Gd} / \mathrm{Ga})$ equal to -10.17 according to relation (6). One value was reported in the literature by Lebedev [4] for the activity coefficient of gadolinium in liquid gallium which is equal to -9.55 at $530^{\circ} \mathrm{C}$. The difference between this value and our determination is probably due to the quite different experimental conditions, the concentration range of gadolinium in gallium used by Lebedev being 100 to 1000 times more important.

Experiments have been performed at several temperatures ranging between 530 and $630^{\circ} \mathrm{C}$ after introducing various quantities of gadolinium in gallium by applying a potential of $-1.6 \mathrm{~V} /$ Ref. The quantity of electrical charge varies from 27 to $49 \mathrm{C}$. The activity coefficient of gadolinium in gallium has been determined from potential measurements realized for each temperature. The different variations as a function of 1000/T are given Fig.4. No influence of $\mathrm{x}(\mathrm{Gd} / \mathrm{Ga})$ was observed. The general variation of the logarithm of the activity coefficient with the reciprocal value of $\mathrm{T}(\mathrm{K})$, determined by this study, is given by the following equation:

$$
\log \gamma(\mathrm{Gd} / \mathrm{Ga})=2.397-\frac{10009}{\mathrm{~T}}
$$

The whole data resulting from the gadolinium study allow us to validate the suggested electrochemical method for the determination of activity coefficients in liquid solvent metals.

\section{5- Electrochemical determination of the activity coefficient of plutonium in liquid gallium}

5.a-Electrochemical study of plutonium in $\mathrm{NaCl}-\mathrm{CaCl}_{2}$ at $560^{\circ} \mathrm{C}$

Plutonium was introduced in melt according to the experimental description given in §3.b. Voltammograms were recorded on a tungsten working electrode to identify the redox systems. Fig. 5 clearly shows one redox system at a potential close to $-1.8 \mathrm{~V} / \mathrm{Ref}$. The reoxidation peak observed during the reverse scan presents a shape characteristic of a deposit oxidation. We can therefore conclude that $\mathrm{PuCl}_{3}$ is reduced to $\mathrm{Pu}$ metal by one electronic step. In order to accurately determine the value of $\Delta \mathrm{E}_{1}$, a galvanodynamic curve was recorded at $0.1 \mathrm{~mA} / \mathrm{s}$ to determine the value of $\Delta \mathrm{E}_{1}$ (Fig. 6) which is equal to $-1.790 \mathrm{~V} / \mathrm{Ref}$.

\section{5.b- Introduction of plutonium in gallium and potentiometric measurement}

To measure $\Delta \mathrm{E}_{2}$, plutonium was introduced in liquid gallium. Voltammograms were firstly realized on a liquid gallium working electrode in order to determine the potential value to be applied for the coulometry. Fig.7 shows the $\mathrm{Pu}(\mathrm{III}) / \mathrm{Pu}$ redox system on gallium electrode (close to $-1.1 \mathrm{~V} / \mathrm{Ref}$ ) and the applied potential chosen to introduce plutonium in 
gallium is $-1.3 \mathrm{~V} /$ Ref. Coulometries at applied potential were performed up to various quantities of electrical charge (from 2 to $7.5 \mathrm{C}$ ). The open circuit potentials were recorded as a function of time to determine the value of $\Delta \mathrm{E}_{2}$, when the steady-state is reached,. Typical curves obtained are given Fig.8A. It shows that the potential, close to $-1.1 \mathrm{~V} / \mathrm{Ref}$ at the beginning of experiment, is not stable and sharply increases around 5000s (or 10000s, depending on the quantity of electrical charge). At the end of experiment, the potential becomes stable but corresponds to the initial potential of liquid gallium without any plutonium. Two assumptions can be made to explain the shape of this non steady-state system:

\#1: Plutonium introduced in gallium is dissolved in melt by reaction with the oxidizing species contained in melt (such as residual chlorine which would not be fully removed after the carbochlorination step).

\#2: Plutonium has a low solubility in gallium and forms with it a solid inter-metallic compound. It is no sense to consider metallic plutonium formation because equilibrium potential of $\mathrm{Pu}(\mathrm{III}) / \mathrm{Pu}$ redox system has been previously measured $\left(\Delta \mathrm{E}_{1}=-1.79 \mathrm{~V} / \mathrm{Ref}\right)$ and is strongly lower than the potential measured during the whole experiment.

\section{5-c. Electrochemical behaviour of a working electrode made of gallium saturated} with plutonium.

To conclude about the assumptions \#1 and \#2, a working electrode constituted of gallium saturated with plutonium was prepared, mixing the two metals: $6.5 \mathrm{~g}$ of gallium and $2 \mathrm{~g}$ of plutonium. In these conditions, for this temperature, and considering the phase diagram of $\mathrm{Pu} / \mathrm{Ga}$ system [8], plutonium precipitates with gallium to form the inter-metallic compound $\mathrm{PuGa}_{3}$. The solubility of plutonium in gallium (mole fraction scale) for a temperature ranging between 500 and $700^{\circ} \mathrm{C}$ is given by the following relation [9]:

$$
\log \mathrm{x}(\mathrm{Pu} / \mathrm{Ga})_{\text {sat }}=2.633-\frac{4036}{\mathrm{~T}}
$$

For a temperature equal to $833 \mathrm{~K}, \log \mathrm{x}(\mathrm{Pu} / \mathrm{Ga})_{\text {sat }}$ is equal to -2.212 . This value being strongly lower than the quantity of plutonium introduced in gallium for the experiment. Voltammograms recorded in the molten salt containing $\mathrm{PuCl}_{3}$ on this working electrode are given in Fig.9. Comparing this curve with the voltammogram given Fig. 7, we observe an oxidation wall at a potential close to $-1.2 \mathrm{~V} /$ Ref corresponding to the oxidation of plutonium dissolved in gallium. The observation of a non limited oxidation process indicates that (i) plutonium is strongly soluble in gallium and (ii) its diffusion in liquid metal is not a rate limiting step of the oxidation process. Accordingly, the high solubility of plutonium in gallium being verified, the variation of open circuit potential of gallium after introducing plutonium by electrolysis (Fig.8A) can only be explained by a re-oxidation of plutonium in the molten salt. The second point in consideration of the first assumption (\#1) is the value of the open circuit potential of the saturated plutonium gallium electrode which is equal to $1.234 \mathrm{~V} / \mathrm{Ref}$. This value is lower than the potential measured after introduction of plutonium in gallium by coulometry (experiment $\$ 5-b$, Fig.8). The formation of an inter-metallic compound with an open circuit potential higher than the one measured for $\mathrm{PuGa}_{3}$ could only be observed for an inter-metallic compounds, $\mathrm{PuGa}_{\mathrm{x}}$ with $\mathrm{x}$ higher than 3 which do no exist at $560^{\circ} \mathrm{C}$ in the phase diagram.

Considering the assumption \#1 realistic, we can resume the experiments performed in $\$ 5 . b$ (Fig.8A) and consider that for short time, at the beginning of the open circuit measurement, plutonium is not yet dissolved in melt. Therefore, we can draw a linear variation of potential at the beginning of experiments and measure y-intercepts (see Fig.8B) which is supposed to 
be $\Delta \mathrm{E}_{2}$. The obtained values for $\Delta \mathrm{E}_{2}$ and the one corresponding to gallium saturated with plutonium are gathered in the Table 1 .

\begin{tabular}{|l|l|l|l|l|}
\hline $\mathrm{Q}(\mathrm{C})$ & $\operatorname{logx}(\mathrm{Pu} / \mathrm{Ga})$ & $\Delta \mathrm{E}_{1}(\mathrm{~V}) / \mathrm{Ref}$ & $\Delta \mathrm{E}_{2}(\mathrm{~V}) / \operatorname{Ref}$ & $\mathrm{emf}(\mathrm{V})$ \\
\hline 2.08 & -4.30 & -1.79 & -1.11 & -0.68 \\
\hline 7.004 & -3.78 & -1.79 & -1.145 & -0.645 \\
\hline 7.425 & -3.75 & -1.79 & -1.136 & -0.654 \\
\hline Pu saturated electrode & -2.212 & -1.798 & -1.234 & -0.564 \\
\hline
\end{tabular}

Table1: Values of emf calculated for several quantities of plutonium in liquid gallium.

These values reported Fig.10 present a linear variation and the theoretical slope $(0.05506$ at $560^{\circ} \mathrm{C}$ ) was reported on the figure. The y-intercept allows to the determination of the logarithm of the activity coefficient of plutonium in liquid gallium. The value obtained is equal to -8.03 (mole fraction scale, pure solid as reference state).

Therefore, the electrochemical procedure can be applied to determine of $\Delta \mathrm{E}_{1}$ and $\Delta \mathrm{E}_{2}$ even if the open circuit potential is not stabilized after introduction of element $\mathrm{M}$ in solvent metal.

\section{6- Conclusion}

The electrochemical method for determining the activity coefficients of elements $\mathrm{M}$ in solvent metal has been validated for gadolinium and plutonium. The logarithms of activity coefficients determined for these two metals in gallium are respectively -10.17 and -8.03 (mole fraction scale) and the variation of $\log \gamma(\mathrm{Gd} / \mathrm{Ga})$ as a function of temperature has been calculated and follows a $1 / \mathrm{T}$ variation.

This electrochemical method doesn't need a large amount of reactive to be performed. Moreover the nuclear materials are confined in a small container and few handling are necessary to realize the experiments. Therefore, this method which is a miniaturized integrated system is very interesting for nuclear applications and particularly could be applied to the determination of the activity coefficients of transuranics.

\section{NOMENCLATURE}

SM : Solvent Metal

MS : Molten Salt

$\mathrm{a}(\mathrm{i})=$ activity of $\mathrm{i}$

$\gamma(\mathrm{i})$ : activity coefficient of i (mole fraction scale, pure solid as reference state)

EFF (M): extraction efficiency of M

$x(i)$ : molar fraction of $i$

$n(i)$ : number of moles of $i$

$\mathrm{n}_{\mathrm{K}}=$ total number of moles of $\mathrm{K}$

$\Delta \mathrm{E}_{\mathrm{x}}$ : potential $(\mathrm{V})$

emf: Electromotive force (V)

$\mathrm{D}$ (i): distribution coefficient

$\mathrm{K}$ : Equilibrium constant of reaction

$\mathrm{R}$ : ideal gas constant $=8.32 \mathrm{~J} \cdot \mathrm{mol}^{-1} \cdot \mathrm{K}^{-1}$

$\mathrm{T}$ : Temperature (K)

$\mathrm{F}=96500 \mathrm{C} \cdot \mathrm{mol}^{-1}$

I: current (A) 


\section{REFERENCES}

1 O. Conocar, N. Douyère and J. Lacquement, J. of alloys and compounds, 389 (2005) 29

2 S. Delpech, G. Picard, Proceeding of Global 2005, Tsukuba, Japon, 2005

3 J. Finne, Thesis, University Pierre et Marie Curie, 2005

4 Lebedev, V.A., "Selectivity of liquid metal electrodes in molten halides",: Metallurgiya, Chelyabinsk, 1993

5 D. Lambertin, S. Ched'homme, G. Bourgès, S. Sanchez, G.S. Picard, J. of Nuclear Mat., 341, 2-3 (2005) 131

6 J. Finne, G. Picard, S. Sanchez, E. Walle, O. Conocar, J. Lacquement, J.M. Boursier, D. Noel., Journal of Nuclear Materials, 344, 1-3 (2005) 158

$7 \quad$ S. Rouquette-Sanchez, G. Picard, J. of Electroanal. Chem., 572 (2004) 173

8 Smithells Metals Reference Book, E.A.Brandles and G.B.Brook editors, Bath, Great Britain, Seventh Edition, 1992

9 F.H. Elinger, C. C. Land and V. O. Struebing, J. of Nuclear Mat., 12, 2 (1964) 226 


\section{KEY OF FIGURES}

Fig. 1: Concentration cell

Fig.2: 1- Experimental set-up with: Glassy carbon cruclible. 2- Electrochemical cell. 3Solvent metal pool. 4- Reference electrode

Fig.3: Variation of $\xi$ calculated as a function of logarithm of $\mathrm{Gd}$ mole fraction introduced in liquid gallium by electrolysis at applied potential.

Fig.4: Variation of $\log \gamma(\mathrm{Gd} / \mathrm{Ga})$ vs $1 / \mathrm{T}$ for various $\mathrm{Gd}$ mole fraction in liquid gallium.

Fig.5: Cyclic voltammogram recorded at $100 \mathrm{mV} / \mathrm{s}$ on a tungsten working electrode $\left(\mathrm{S}=0.542 \mathrm{~cm}^{2}\right)$ in $\mathrm{NaCl}-\mathrm{CaCl}_{2}$ molten salt at $560^{\circ} \mathrm{C}$ containing $0.042 \mathrm{~mol} / \mathrm{kg}$ of $\mathrm{PuCl}_{3}$.

Fig.6: Galvanodynamic curve realized at $0.1 \mathrm{~mA} / \mathrm{s}$ on tungsten working electrode in $\mathrm{NaCl}$ $\mathrm{CaCl}_{2}$ molten salt at $560^{\circ} \mathrm{C}$ containing $0.042 \mathrm{~mol} / \mathrm{kg}$ of $\mathrm{PuCl}_{3}$.

Fig.7: Cyclic voltammogram realized at $10 \mathrm{mV} / \mathrm{s}$ on liquid gallium electrode $\left(\mathrm{S}=1.3 \mathrm{~cm}^{2}\right)$ in $\mathrm{NaCl}-\mathrm{CaCl}_{2}$ molten salt at $560^{\circ} \mathrm{C}$ containing $0.042 \mathrm{~mol} / \mathrm{kg}$ of $\mathrm{PuCl}_{3}$.

Fig.8: A- Open circuit potential measured as a function of time on a liquid gallium electrode after introducing plutonium by electrolysis at applied potential $(\mathrm{E}=-1.3 \mathrm{~V} / \mathrm{Ref})$ curve (1): $\mathrm{Q}=$ 2.08C (corresponding to $\left.\mathrm{x}(\mathrm{Pu})=4.96 .10^{-5}\right)$. Curve $(2)$ : $\mathrm{Q}=7.425 \mathrm{C}$ (corresponding to $\mathrm{x}(\mathrm{Pu})=$ $\left.1.77 .10^{-4}\right)$

B- Zoom of curve A at the beginning of the measurements.

Fig.9: (a)- Cyclic voltammogram realized on a liquid gallium electrode saturated with plutonium in $\mathrm{NaCl}-\mathrm{CaCl}_{2}$ molten salt at $560^{\circ} \mathrm{C}$ containing $0.042 \mathrm{~mol} / \mathrm{kg}$ of $\mathrm{PuCl}_{3}$. (b) see curve given Fig.7

Fig.10: Variation of $\xi$ calculated as a function of the logarithm of the mole fraction of plutonium contained in liquid gallium. 
FIG.1

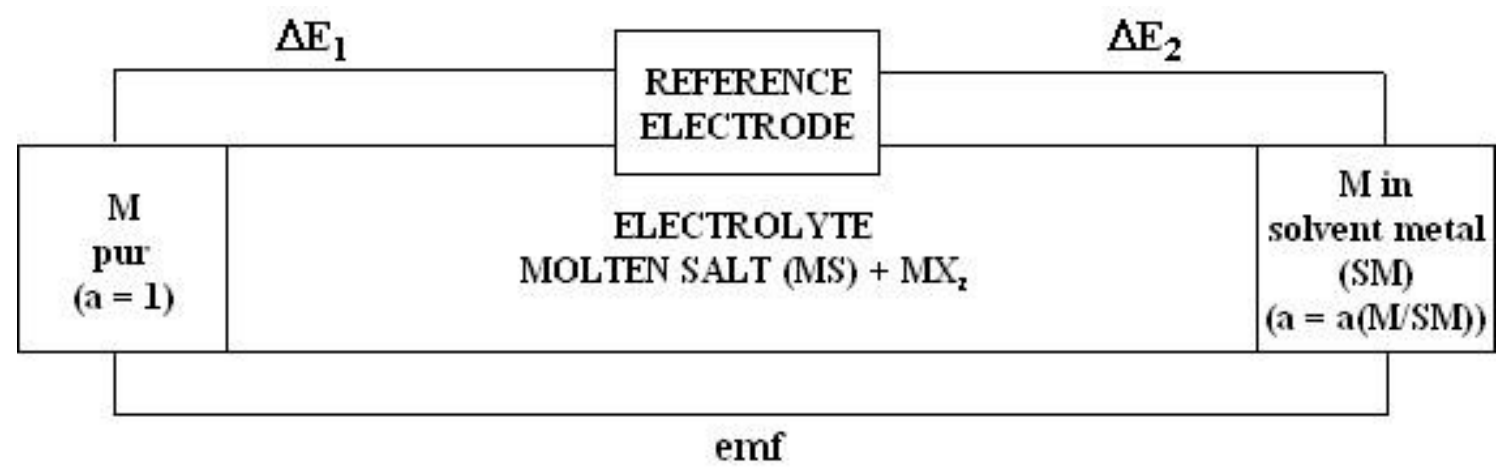


FIG.2

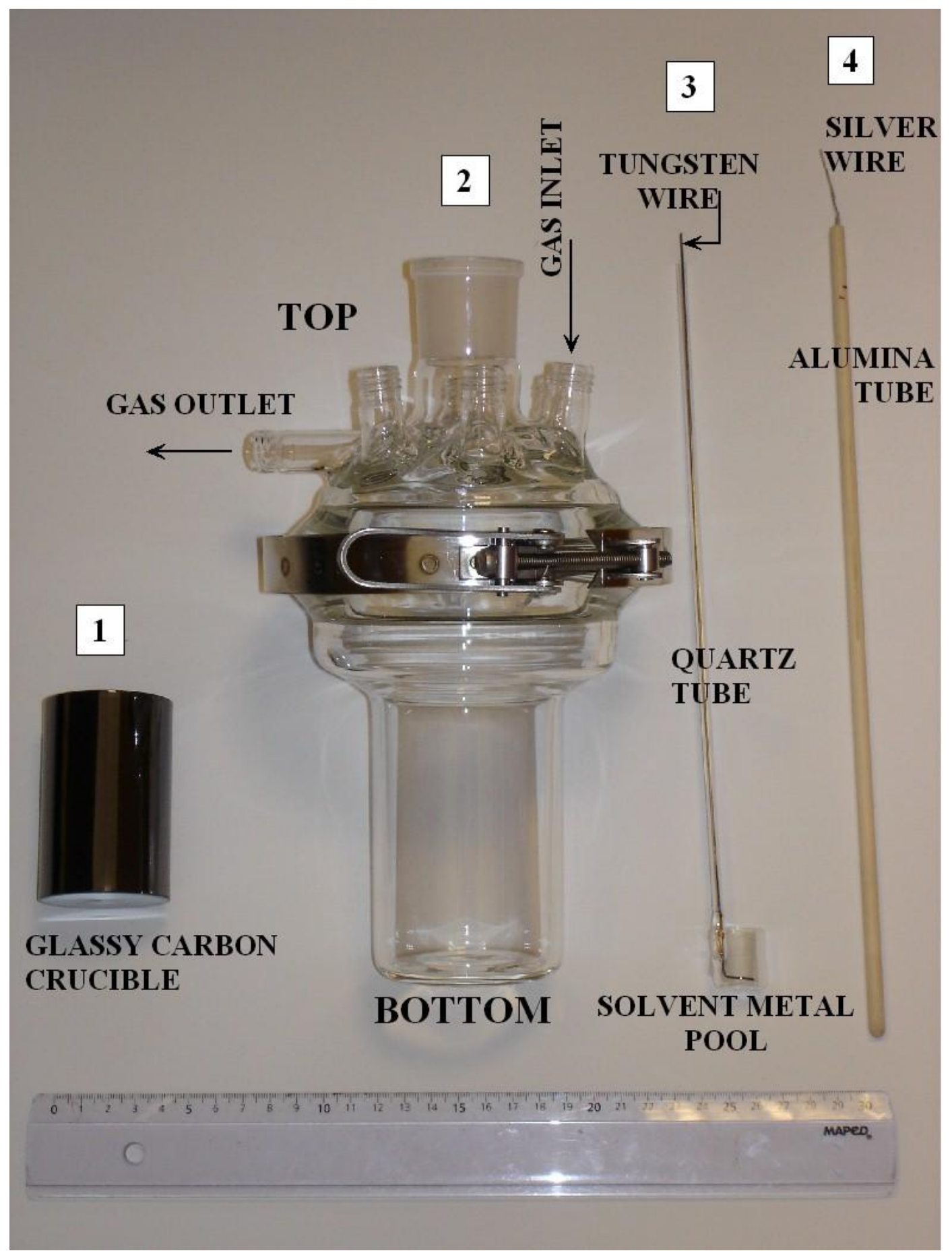


FIG.3

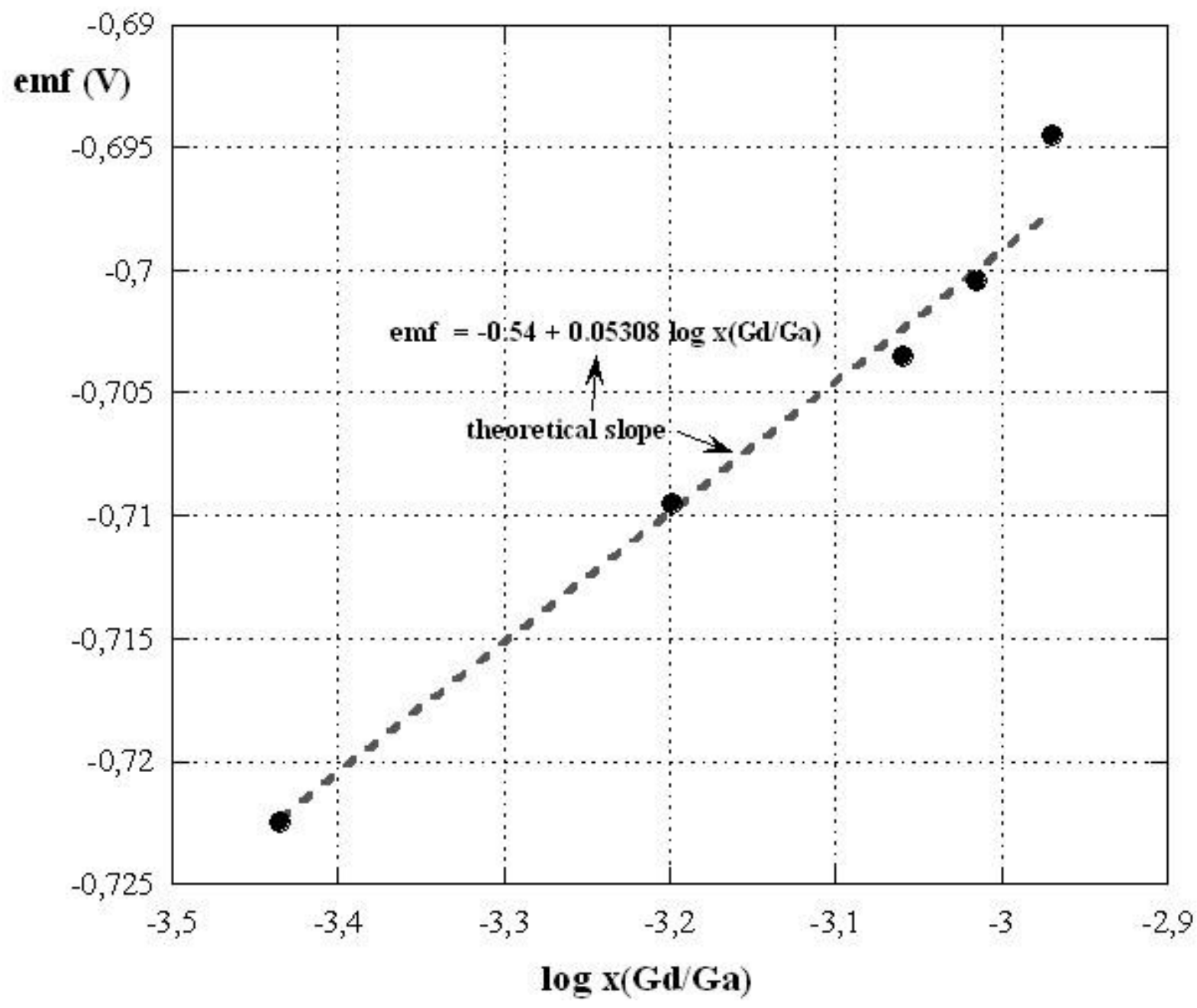


FIG. 4

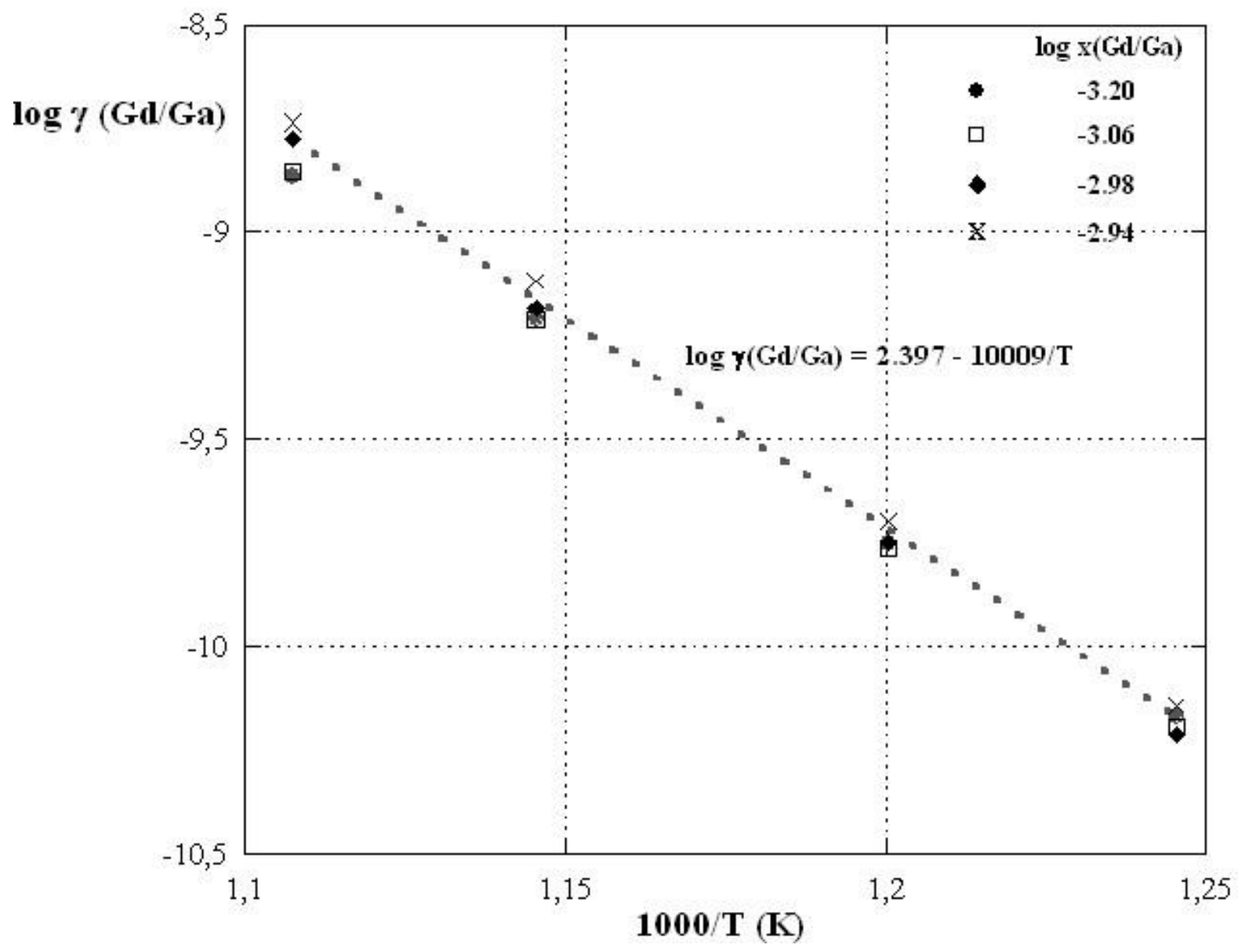


FIG. 5

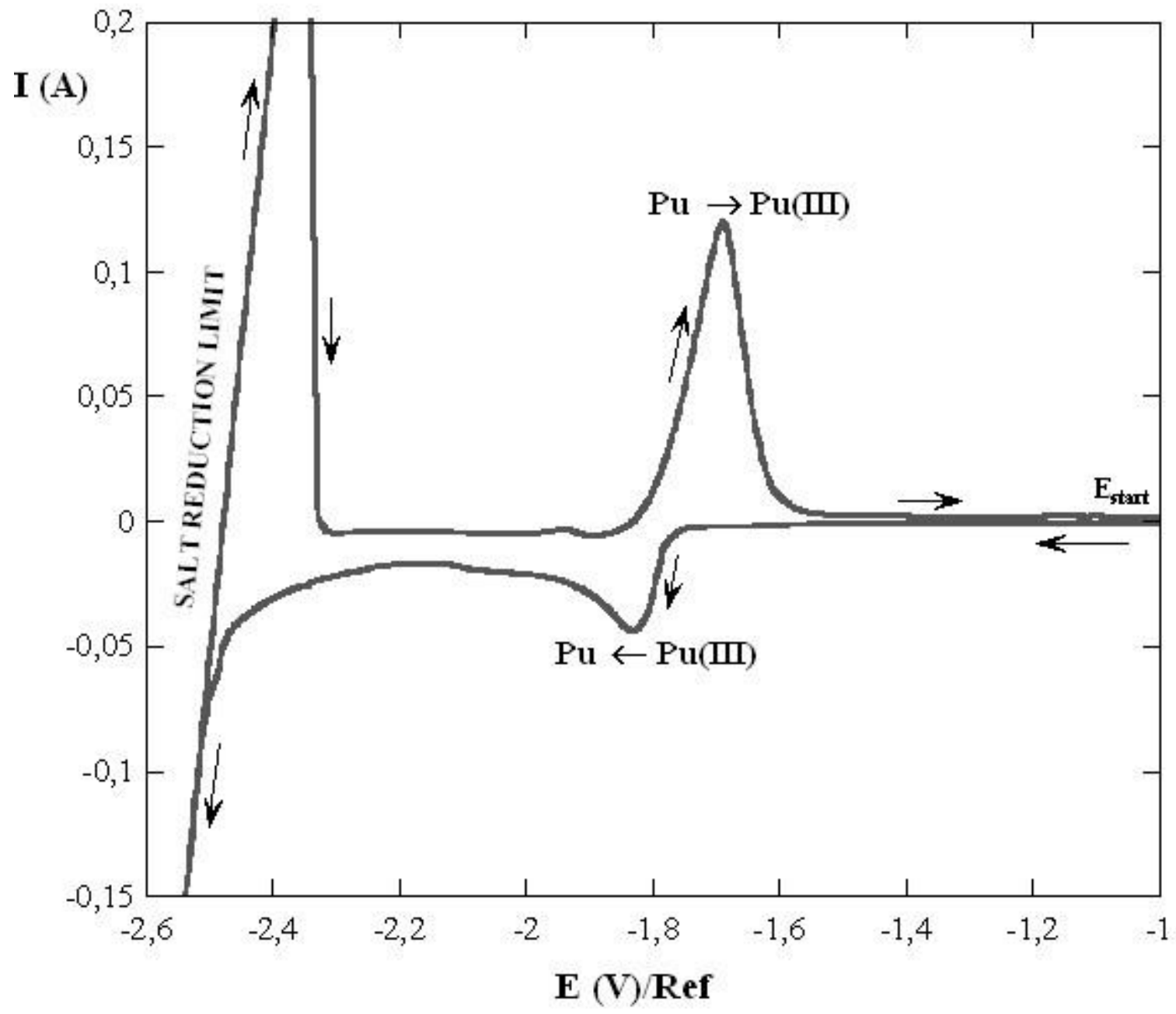


FIG. 6

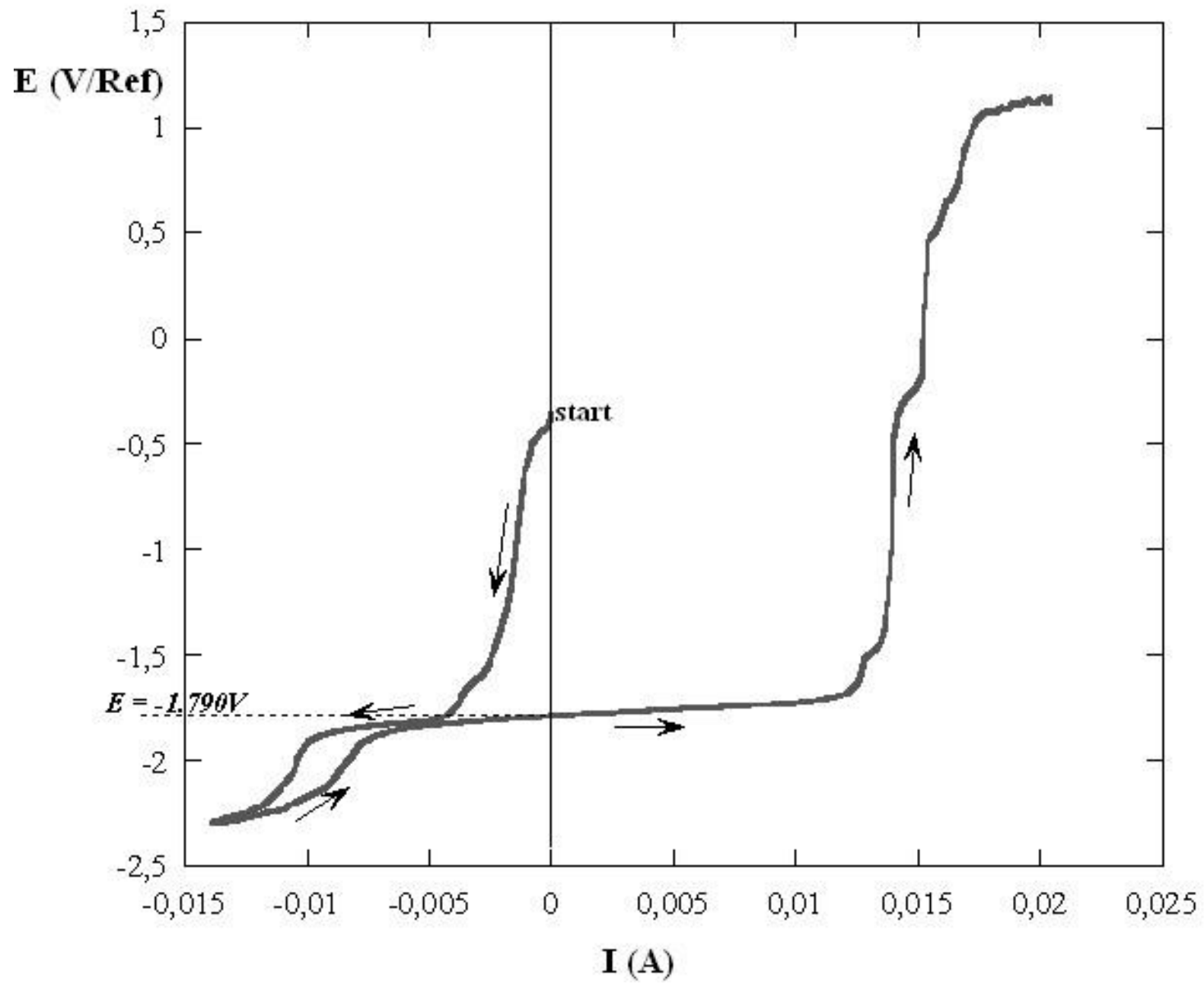


FIG.7

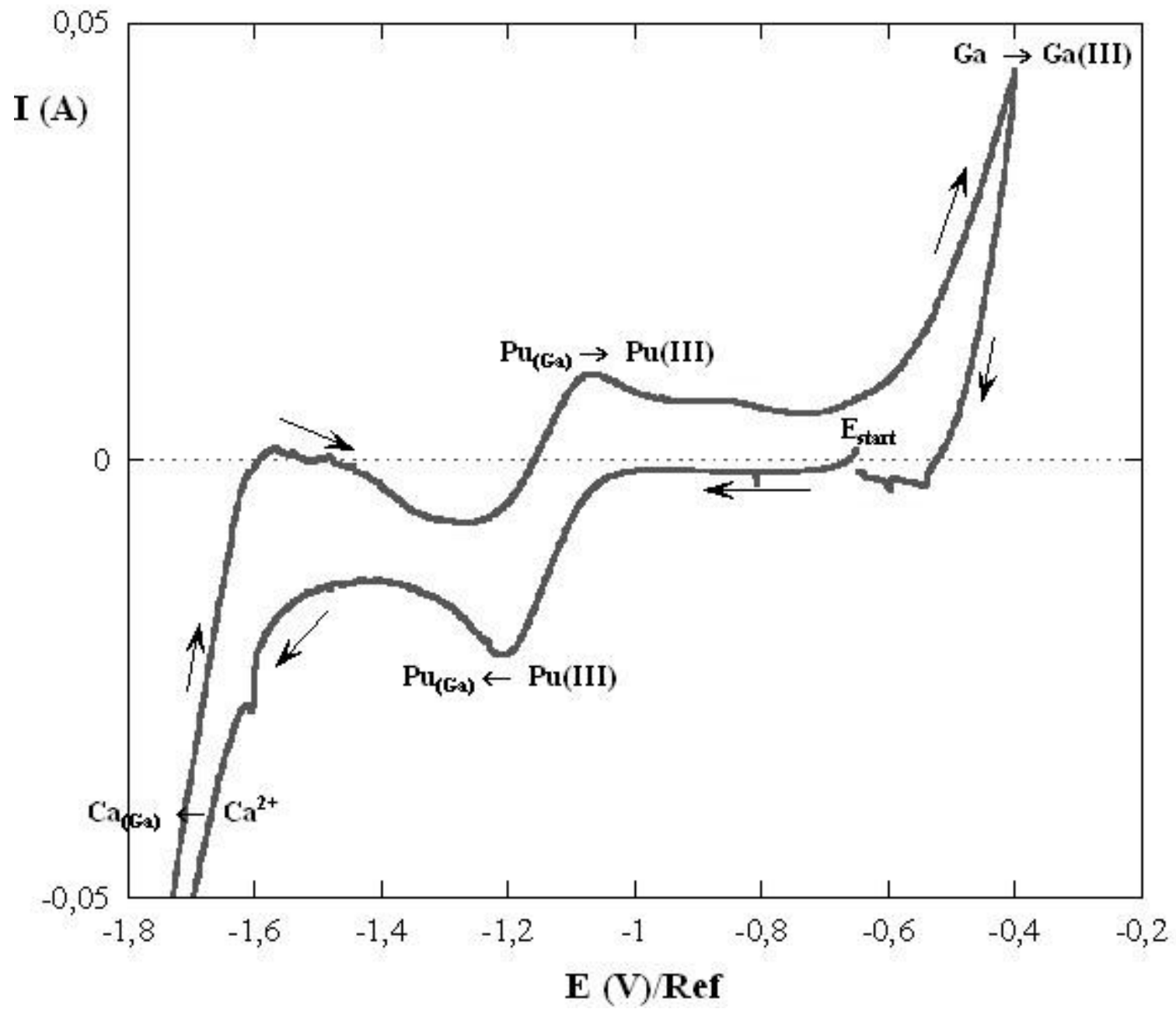


FIG. 8
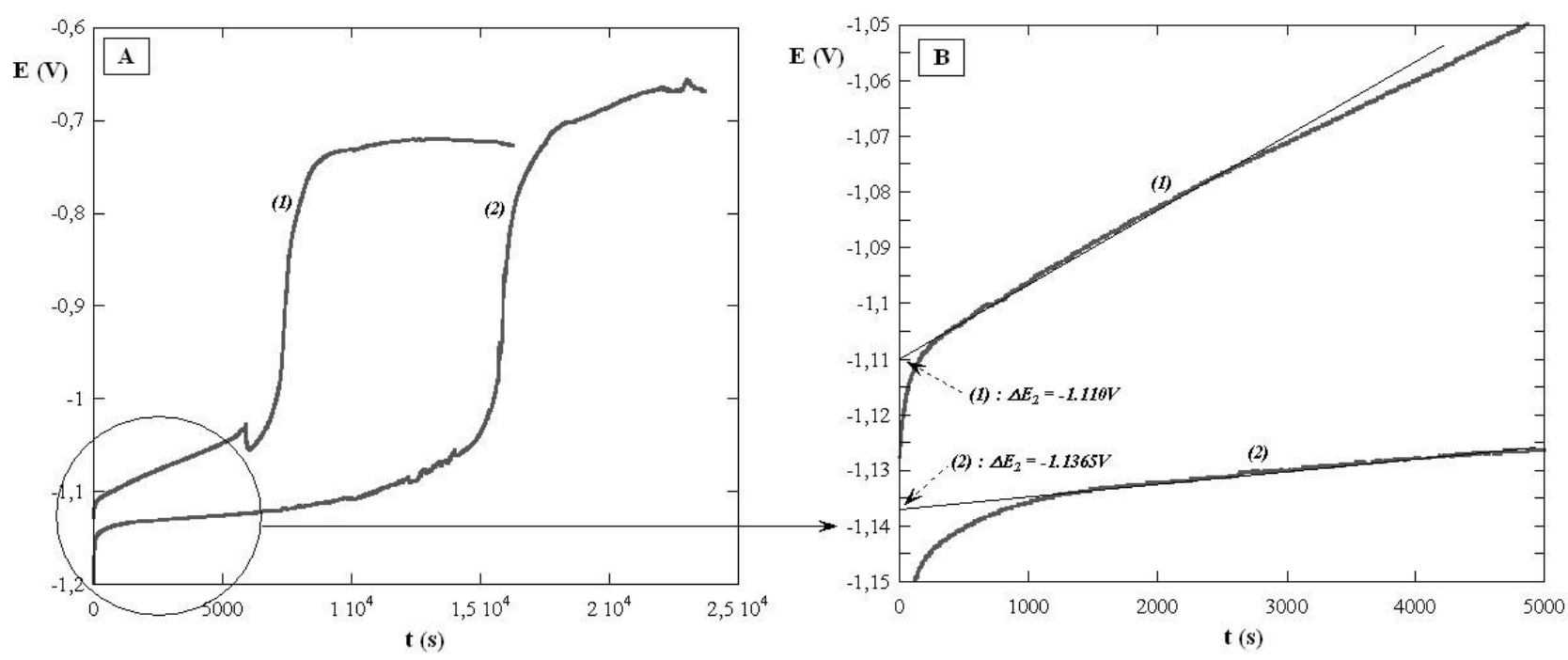
FIG.9

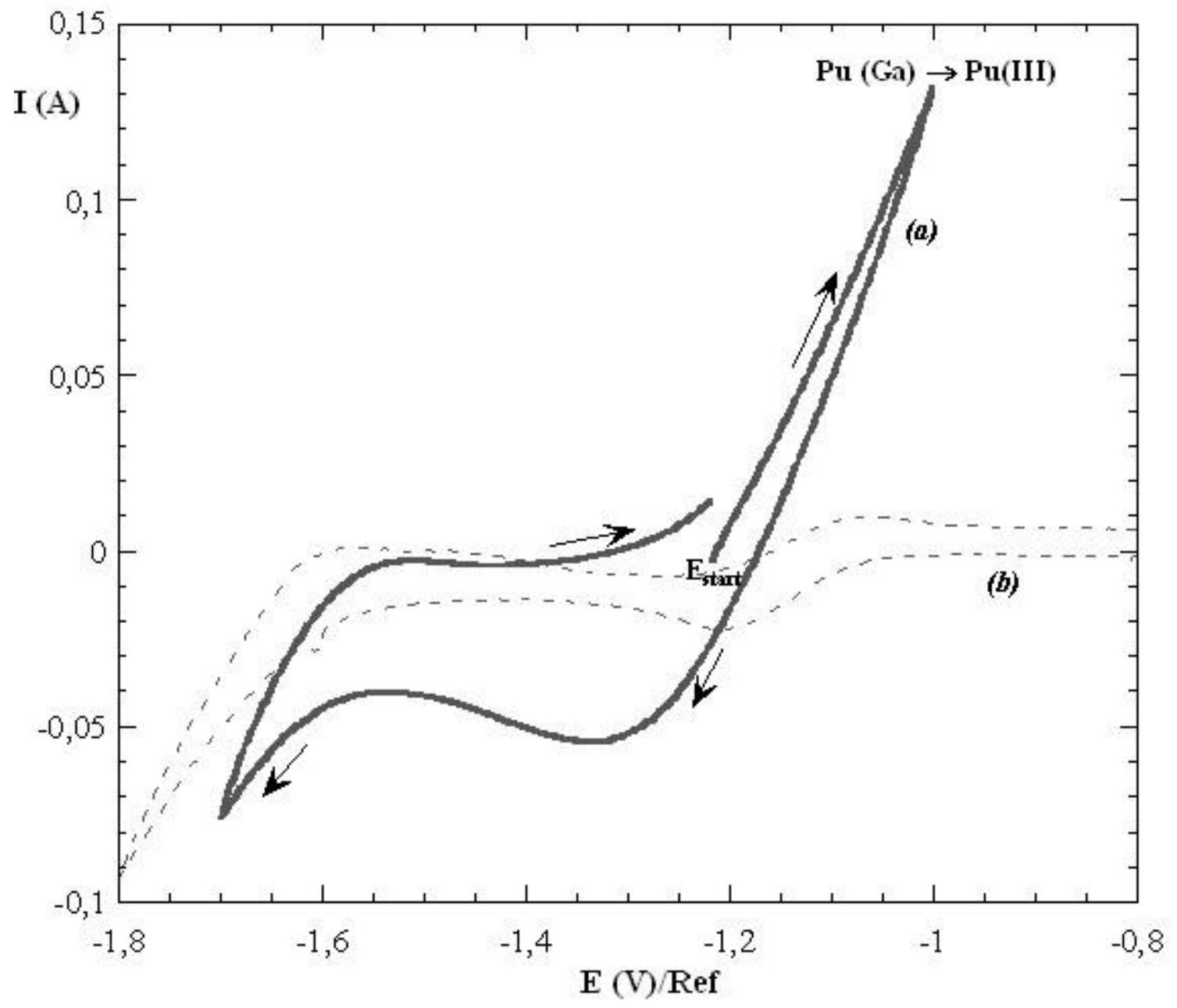


FIG.10

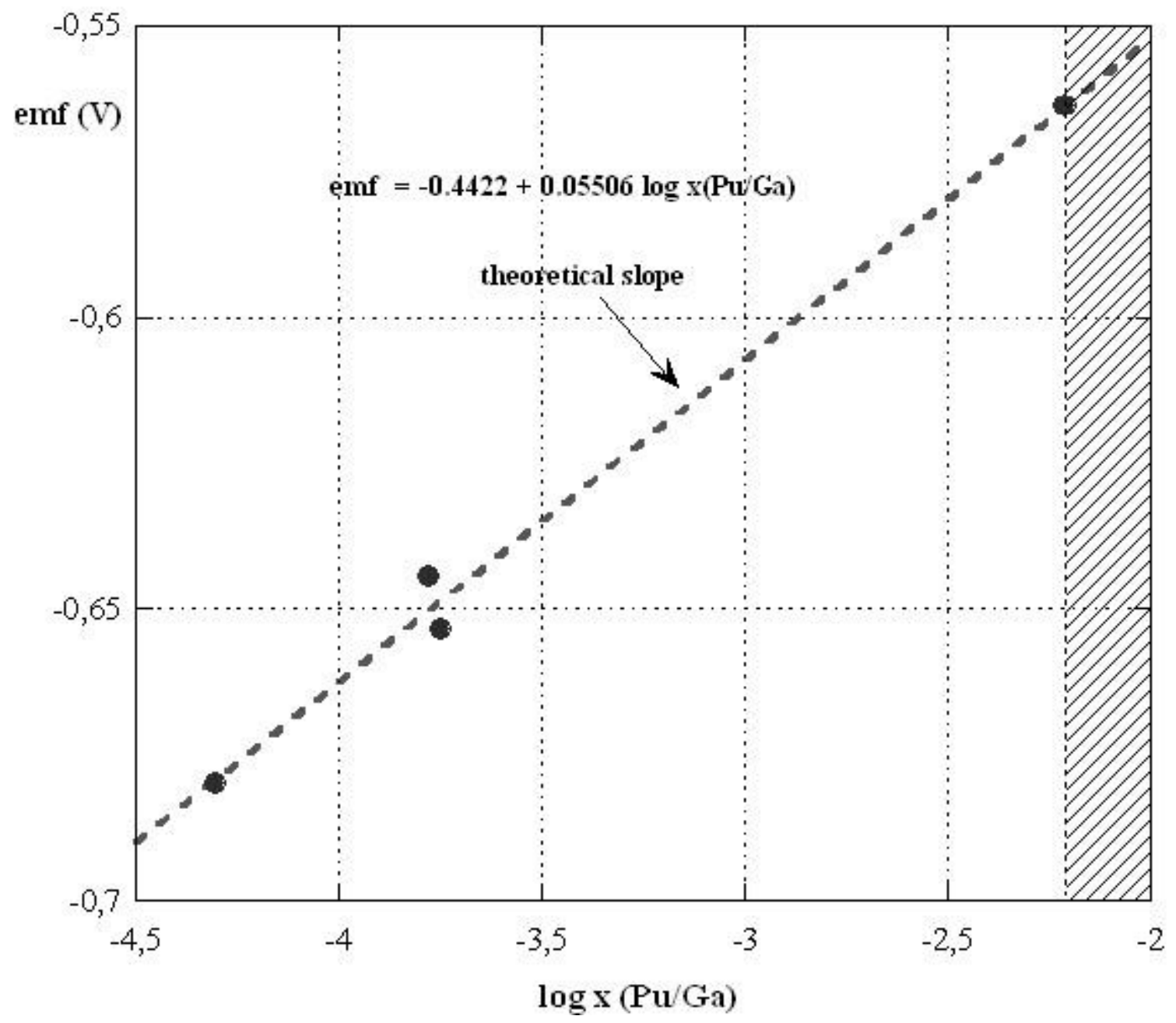

